Res Pública Revista de Historia de las Ideas Políticas

ISSN: 1131-558X

http://dx.doi.org/10.5209/rpub.69642

\title{
“Quel Reyno manda al Rey: y no el Rey al Reyno". La legitimidad de Carlos I en el tiempo de las comunidades de Castilla quinientos años después
}

\author{
Salvador Rus Rufino* \\ Recibido: 20 de mayo de 2020 / Aceptado: 13 de junio de 2020
}

Resumen. Entre mayo de 1520 y abril de 1521 se desarrolló en Castilla un movimiento político y social conocido con el nombre de Comunidades. Los líderes de este movimiento fueron capaces de levantar a catorce ciudades contra la política de Carlos I, futuro Emperador Carlos V, y sus colaboradores. El artículo está construido seleccionando tres hechos históricos que dieron lugar a la discusión entre los comuneros y los partidarios del Emperador Carlos durante este período de tres conceptos políticos fundamentales: legitimidad monárquica, la representación política y la monarquía pactada. La cuestión fundamental fue determinar qué institución tenía preeminencia el rey o el reino a través de sus representantes.

Palabras clave: Comunidades; Castilla; libertad; monarquía; pacto; representación política; legitimidad.

[en] "That the Kingdom Commands the King: and not the King to the Kingdom". The Legitimacy of Charles the First at the Time of the Communities of Castile Five Hundred Years Later

Abstract. The Comunidades was a political and social movement which development from May 1520 to April 1521 in Castile. The leaders of this movement were able to raise fourteen cities against the politics of Charles I, future Emperor Charles V, and his collaborators. The article is built by selecting three historical facts that led to discussion between the comuneros and followers of Emperor Charles. Three political concepts were discussed during this period: monarchical legitimacy, political representation and agreed monarchy. The fundamental question was to determine what institution had preeminence the king or the kingdom through its representatives.

Keywords: Communities; Castile; Freedom; Monarchy; Pact; Political Representation; Legitimacy.

Sumario. 1. Hechos. 2. ¿Puede autoproclamarse un rey? 3. Carlos I y Castilla. 4. Carlos V Emperador. 5. El rechazo al Imperio. 6. Conclusiones. 7. Bibliografía.

Cómo citar: Rus Rufino, S. (2020). "Quel Reyno no manda al Rey: y no el Rey al Reyno”. La legitimidad de Carlos I en el tiempo de las Comunidades de Castilla quinientos años después. . Res Pública. Revista de Historia de las Ideas Políticas, 23(2), 151-161.

\section{Los hechos}

Para comprender el sentido de esta frase ${ }^{2}$ que hace referencia al punto más importante de discusión entre el rey Carlos I y sus representantes y los comuneros, hay que considerar unos hechos y unas fechas fundamentales que sirvieron para organizar este movimiento social y político en varias ciudades del reino de Castilla.

El primer hecho fue la proclamación de Carlos I como rey de Castilla en vida de su madre la reina Juana
I. El suceso acaeció en 1516 en Bruselas en la iglesia de Santa Gúdula. Al finalizar el funeral que se celebró en memoria de su abuelo Fernando el Católico. Para algunos historiadores esto fue un auténtico golpe de estado ${ }^{3}$.

Esta manera de proceder se podría justificar porque el último testamento del rey Fernando el Católico, que ejercía como regente de Castilla, pocas horas antes de fallecer dejaba como heredero a su nieto Carlos de Gante, porque su hija Juana I, reina propietaria de Castilla, no estaba capacitada para gobernar y se encontraba confina-

Universidad de León

srusr@unileon.es

M. Danvila y Collado, Historia crítica y documentada de las Comunidades de Castilla, Volumen II, Madrid, Establecimiento Tipográfico de la viuda e hijos de M. Tello, 1898, p. 536 contestación del Almirante de Castilla dio a la carta que la Junta de Tordesillas de 22 de noviembre de 1520. Por ejemplo, J. Pérez, La revolución de las Comunidades de Castilla, Siglo XXI Editores, Madrid, 1977, pp. 21 y 115.

3 Una copia del testamento original en Archivo de la Corona de Aragón, ACA, CANCILLERÍA, Registros, Núm. 3604, fol. 274r-290r. Este testamento invalidó los dos anteriores de Burgos 2 de mayo de 1512 y Aranda de Duero 26 de abril de 1515, en los que disponía que su nieto Fernando debía asumir las regencias de Castilla y de Aragón, hasta que su hermano Carlos, el legítimo heredero, viniese a hacerse cargo de su gobierno. Edición del mismo Testamento del Rey Fernando el Católico. 22 de Enero de 1516, Original conservado en la Fundación Casa de Alba, estudio y transcripción de J.M. Calderón, Testimonio Compañía editorial, Madrid, 2013. Cf. A. Sáenz de Santa María Vierna, "El testamento del Rey Católico y la legítima aragonesa", Revista de Derecho Civil Aragonés, 21-22, 2015-2016, pp. 155-172. 
da en Tordesillas. En este testamento ${ }^{4}$ se dispuso la unión de las dos coronas, Castilla y Aragón. Este hecho significó el advenimiento de una nueva dinastía y la definitiva exclusión del infante Fernando ${ }^{4}$, el hijo menor de Juana y Felipe el Hermoso, nacido y criado en Castilla, de la sucesión en la Corona. Las disposiciones testamentarias de Fernando el Católico en su último testamento fueron un acierto que evitaron problemas sucesorios en España, una confrontación fratricida que habría, sin duda, divido al Reino entre los partidarios de Carlos y Fernando provocando una guerra civil y afianzó la legitimidad y la legalidad de Carlos para ceñirse la corona de los reinos unidos en una persona. El sueño de los Reyes Católicos se había cumplido en la persona de su nieto.

El segundo, la llegada de Carlos I a la Península un 18 de septiembre de 1517 . El monarca salió el puerto de Flesinga con su escuadra acompañado de un nutrido séquito de colaboradores. Este hecho provocó más tarde un fuerte rechazo porque el comportamiento de los flamencos fue propio de unos conquistadores que venían a esquilmar el reino. Fue unos de los motivos que esgrimieron los comuneros para conseguir adhesiones a su causa y alentar la revuelta.

El tercero, la precipitada salida del rey Carlos I desde La Coruña un 20 de mayo de 1520 rumbo a Flandes y, posteriormente, a Aquisgrán para recibir el título de Emperador del Sacro Imperio Romano Germánico ${ }^{5}$. La elección imperial era muy costosa porque había que atender las demandas económicas de los siete electores ${ }^{6}$ y sufragar los gastos del viaje para la proclamación. Carlos I se vio obligado a solicitar un servicio (impuesto extraordinario) a las Cortes. Se concedió después de cinco votaciones y un traslado de sede. Esta demanda económica para gastar el dinero de Castilla en una empresa extranjera, también se convirtió en uno de los motivos para provocar la revuelta de los Comuneros.

\section{2. ¿Puede autoproclamarse un rey?}

Castilla esperaba y deseaba tener un rey que tomara las riendas del gobierno del reino. Desde la muerte de la reina Isabel la Católica en 1504, se habían vivido momentos complicados y la inestabilidad, unida a las malas cosechas y a la ausencia de un gobierno ampliamente reconocido, habían provocado una situación de decadencia, abatimiento y pesimismo entre los castellanos. Este estado de ánimo contrastaba con otra realidad, Castilla se había convertido en un reino poderoso, prestigioso y con muchos recursos dentro de la Cristiandad.

La autoproclamación de Carlos en Flandes provocó indignación, rechazo y conmoción en Castilla. Pedro Mártir de Anglería informó por extenso a su pariente y hombre de confianza del príncipe Carlos, Luis Marliani, obispo de

\footnotetext{
Cf. la breve biografía de A. Alvar Ezquerra en http://dbe.rah.es/biografias/10081/fernando-i-de-austria (consultado el 15/5/2020). Con una bibliografía muy selecta.

5 Su abuelo Maximiliano I murió el 12 de enero de 1519. El 28 de junio de 1520 fue elegido Rey de los Romanos en Frankfurt am Main.

6 Los arzobispos de Maguncia, Tréveris y Colonia, el Rey de Bohemia, el Conde Palatino del Rin, el Duque de Sajonia y el margrave de Brandeburgo. Tres eclesiásticos y cuatro seculares.
}

Tuy, sobre las altas expectativas que estaba generando la llegada del príncipe a España. Castilla estaba dispuesta a servir a un buen rey, como habían sido los Reyes Católicos, pero debía respetar las leyes y las costumbres porque "la perversión de las leyes suele convertir el amor en odio"7. Le aconsejaba que no se proclame "Rey de las Españas" porque aún vivía su madre y si deseaba gobernar Castilla, lo podría hacer igualmente con el título de príncipe, porque un príncipe debe gobernar buscando el bien de los súbditos y del reino, de lo contrario los súbditos se rebelarán contra el monarca y lo consideraran un tirano.

Nadie dudaba sobre los derechos del príncipe Carlos para ser en el futuro rey. Lo que se criticó por parte de los castellanos fue la urgencia en querer ser reconocido como Rey de las Españas en vida de su madre, cuando ni era necesario, ni era oportuno. Lo único que podía causar este paso era división y animadversión hacia su persona $^{8}$. Muestra de la delicadeza con que se toma el asunto es la carta que escribió el Consejo Real al príncipe que recogió Prudencio Sandoval ${ }^{9}$, quizás inspirada en gran parte por el Cardenal Cisneros. En la misiva se relataban los problemas, las divisiones y los abusos que se estaban produciendo en el Reino y se le suplicaba que viniera cuanto antes para que estos desórdenes no se generalizaran y se castigara a los culpables con severidad, porque sus acciones constituían un "menosprecio a vuestra Real justicia" (p. 63).

A reglón seguido se le aconsejaba que no se tomara el título de rey porque "nos pareció que no devia V. A. hazer ni conuenia que se hiziesse para lo de Dios: y para lo del mundo: porque teniendo como V. A. tiene tan pacíficamente sin contradicción de estos Reynos, que en efecto desde luego libremente son vuestros ..., no ay necessidad en vida de la Reyna nuestra señora vuestra madre intitular Rey, pues lo es. Porque aquello seria disminuyr el honor y la reuerencia que se deue por ley divina, y humana, a la Reyna nuestra Señora y vuestra madre, y venir sin fruto ni efeto ninguno contra el mandamiento de Dios, que os ha de prosperar y guardar para reynar por muchos y largos años" (p. 63). Estas líneas contienen una idea muy importante. Si Carlos se proclamaba rey, estaba imponiéndose a sus súbditos, es decir, usaba su poder para convertirse en monarca. En cambio, si esperaba a que la proclamación se realizara en Castilla, entonces estaba recibiendo el reconocimiento por parte de la sociedad castellana y se estaba invistiendo no sólo de poder como rey, sino que se le reconocía autoridad para gobernar. La diferencia entre imponerse y obtener el reconocimiento necesario para ser

P. Mártir de Anglería, Epistolario, volumen III, editado por J. López de Toro, Madrid, Imprenta de Góngora, 1956, carta 568, pp. 221222. "Conseguiréis cuanto pidáis a Castilla, pues no aprendió otra cosa que la obediencia a sus Reyes, si gobernaban conforme a justicia, según es la obligación del soberano; pero me doy cuenta de que se muestran reacios a admitir las novedades".

P. Sandoval, Historia de la vida y hechos del Emperador Carlos V, Primera parte, Barcelona, Sebastián Cormellas, 1625, Primera parte, 2. 4, p. 59 relata la proclamación como Rey de España en Bruselas; A. de Santa Cruz, Crónica del Emperador Carlos V, cinco volúmenes. Editado por R. Beltrán y Rózpide, A. Blázquez y Delgado Aguilera, y F. Laiglesia y Auser. Madrid, Imprenta del Patronato de Huérfanos de Intendencia e Intervención Militares, 1920, I, I, XXVIII, pp. 108-113 añade que el hecho en Castilla causó conmoción, indignación e ira contra el príncipe Carlos.

P. Sandoval, op. cit., Primera parte, 2. 4, pp. 62-64. 
rey es abismal. Una vez más aflora la antigua controversia entre auctoritas y potestas ${ }^{10}$.

¿Qué sentido tenía esta distinción? Se un rey obtiene el reconocimiento se convertía en un monarca aceptado que garantizaba la libertad de sus súbditos y vivía para lograr el bien del reino. Los súbditos, ante los posibles abusos y desviaciones de poder, podían reclamar a la autoridad del monarca, o acudir a las Cortes, que era la institución política representativa que controlaba el ejercicio del poder y podía poner remedio a las situaciones injustas.

Después con mucho tacto exponía que sus derechos para ser rey de Castilla no se incrementaron con la muerte de su abuelo Fernando el Católico, "pues estos Reynos no eran suyos". Recordaba que su abuelo ejercía la regencia en nombre de su madre por expreso deseo de ella. E insistía en que si se proclama rey crearía división, controversias y luchas entre facciones, que se alinearán unos con él y otros con su madre la reina. De esta manera se quebraría la paz en Castilla y se destruiría la unión y la armonía entre sus súbditos. Esa no era, a juicio del Consejo Real, la mejor manera de iniciar un reinado. El rey debía fomentar y garantizar la unión, la concordia, la paz y la armonía en el reino. La carta finalizaba con una advertencia. Los hijos que quitaban "el honor" y usurpaban la dignidad real que no les correspondían en vida del padre, "reynaron poco, y con trabajo y contradicion" (p. 64). Parece que la carta del Consejo Real anunciaba lo que iba a suceder pocos años después, aunque el reinado de Carlos I fue largo.

¿Por qué no admitió una parte de los castellanos a Carlos como rey? Porque el acto de proclamación en Flandes, aunque estuviera avalado por el Papa y por otros monarcas, era jurídicamente incompleto e insuficiente para ejercer las funciones de un monarca. Los súbditos de Castilla -también los de Aragón- en una sesión de Cortes tenían que jurar fidelidad al nuevo rey y, al mismo tiempo, el príncipe juraba respetar los fueros y las leyes del reino. Para completar su proclamación, Carlos tenía que venir a España y ser jurado en cada una de las Cortes. Lo consiguió entre los años 1518 y 1519 en las Cortes de Valladolid, Zaragoza y Barcelona. Desde el punto de vista jurídico cada reino tenía sus Cortes y el juramento se hacía en ellas. Porque las Cortes eran del reino, no para el rey.

La premura para conseguir jurar en cada reino venía impuesta por un motivo político, había prisas por ser proclamado Rey de Castilla y Rey de Aragón para conseguir presentarse como candidato a la nominación imperial y conseguir ceñirse la corona del Sacro Imperio

\footnotetext{
La autoridad (auctoritas) es, pues, un saber socialmente reconocido. Esto implica libertad, porque el reconocimiento es una aceptación libre por parte de otro. La cantidad de libertad en juego está en función de la auctoritas en el ámbito público dentro del marco de la libertad reconocida. La potestad (potestas), en cambio, es el poder socialmente reconocido. De este modo, está claro que la autoridad, en el lenguaje común, es algo que se atribuye a alguien: se es autoridad en ... algo. De la misma forma que se suele decir se tiene potestad para ... lo que sea. Es decir, las locuciones marcan una sutil, pero clara diferencia entre ambas connotaciones del poder. Así la autoridad hace referencia a una nota esencial del ser personal, en su entendimiento; mientras que la potestad hace referencia a la otra nota esencial, a la voluntad, al querer, a lo operativo. En este sentido es en el que se van a emplear aquí esta distinción clásica del poder entre auctoritas y potestas, y se puede tomar como comienzo de definición de una estructura del poder.
}

Romano Germánico como hicieron su bisabuelo, Federico III, y su abuelo, Maximiliano $\mathrm{I}^{11}$.

Este hecho, que para uno constituyó un acierto y para otros un error, moverá a los comuneros a plantear una cuestión de legalidad y, también, de legitimidad dinástica. La reina era Juana I a la que consideraban capaz de gobernar si se le permite salir de su prisión de Tordesillas y se la trataba con los remedios médicos adecuados. Antes de que los comuneros se encontraran con la reina de Castilla en Tordesillas, acaecieron otros hechos que fueron, junto con el que hemos expuesto, los detonantes de la rebelión.

\section{Carlos I y Castilla}

La manera de gobernar y las costumbres borgoñonas que traía el príncipe Carlos a Castilla no gustaron, la impresión que causó fue muy poco favorable y no cumplió con las expectativas que se habían creado sus súbditos. No sabía hablar castellano, estaba rodeado de consejeros y personas de confianza flamencos, quien dirigía todo era su preceptor y hombre de confianza Guillermo de Croy $^{12}$, el señor de Chièvres. Carlos I se mostró como un monarca altivo, inaccesible y concedió todos los cargos de responsabilidad a extranjeros ${ }^{13}$. Esta forma de conducir los asuntos de gobierno molestó a todos los estamentos sociales, especialmente a los nobles y a la burguesía ciudadana, porque se veían excluidos de las responsabilidades y asuntos políticos. Además, los extranjeros se comportaban como conquistadores, que querían extraer toda la riqueza posible de Castilla ${ }^{14}$.

El desembarco de la corte flamenca provocó un choque de mentalidades y de costumbres entres los borgoñones y los castellanos. Los primeros veían en Castilla la posibilidad de un ascenso social y político y un territorio que permitía un enriquecimiento rápido. Los segundos querían conservar sus leyes tradicionales y seguir la vida como hasta entonces, aprovechando las oportunidades que ofrecía la ampliación del reino con el descubrimiento de las tierras de América. Los unos concebían la vida como una fiesta y un derroche continúo, los otros vivían de una forma sobria, templada y austera ${ }^{15}$. Es muy ilus-

11 J. J. Jerez Calderón, Pensamiento político y reforma institucional durante la guerra de las Comunidades de Castilla (1520-1521), Madrid, Marcial Pons, 2007, pp. 119-125.

12 Fue quien sustituyó a Margarita de Austria, viuda del príncipe Juan de Trastámara y tía de Carlos, en la tutela del príncipe Carlos en 1515 cuando éste fue declarado mayor de edad.

13 M. Danvila y Collado, op.cit., Vol. II, p. 586, "e tanbien los oficios beneficios tenencias que nos pertenescen por nación e leyes destos rreynos todos se an dado a estrangeros e no naturales e si algún natural nuestro algun oficio o beneficio a avido a sido conprado por sus dineros de los estrangeros e aun con todo esto que se ha sofrido por malas yndustrias e malsinerías de nuestros naturales e sobre avernos llevado lo bueno e desfrutado estos reynos nos tienen tanto odio e enemistad como si verdaderamente fuésemos sus propios enemigos e omecidas de sus padres e en toda la casa rreal no an consentido queste una persona de nuestra nación".

14 J. M. Maravall, Las Comunidades de Castilla. La primera revolución moderna, Madrid, Alianza Editorial, 1984, 4ºd., pp. 62-63.

15 El rey Carlos I necesitaba diariamente 150.000 maravedíes, en cambio los Reyes Católicos gastaban 15.000. Para J. Maldonado, Historia de la revolución conocida con el nombre de las Comunidades de Castilla, Imprenta de D. E. Aguado, Madrid, 1840, traducción de J. Quevedo, p. 288: “Era tan estremada la confianza que el rey había 
trativa la información que nos transmite un testigo de la época y de los acontecimientos Pedro Mártir de Anglería: "No es justo que los asuntos de España sean encauzados por los dictámenes de los flamencos del norte. Su mentalidad y educación distan mucho de las costumbres españolas. Su Dios son los placeres: cierta sobria elevación de mente de los españoles, con la vista puesta en el honor, hace a éstos más moderados. Dicen en cambio, que el Rey, por naturaleza -ya que es más sobrio-se muestra enemigo de juerguistas y borrachos"16. Abundan los testimonios sobre el descontento generalizado que protagonizaron los acompañantes flamencos sobre los castellanos. Para ellos Castilla era tierra conquistada y sus habitantes unos súbditos a los que había que someter ${ }^{17}$. En estos primeros años el rey no supo atraerse a sus súbditos. Éstos se sintieron maltratados como si fueran sus enemigos ante los que tenía que tener prevención y combatir ${ }^{18}$.

Una de las decisiones que causaron más rechazo y animadversión fue el nombramiento del Cardenal Guillermo Jacobo de Croy como administrador del arzobispado de Toledo $^{19}$, sobrino del todopoderoso señor de Chièvres. Este nombramiento querido y planeado directamente por el rey, causó indignación, frustración y enojo entre los eclesiásticos y la nobleza, que esperaban un eclesiástico natural de Castilla, para tan importante y rica sede episcopal. El rey, en cambio, quería aprovechar la ocasión para demostrar su poder imponiendo un candidato afín a sus ideas y proyectos políticos. En los Capítulos de la ciudad de Valladolid, se reiteró la petición realizada en las Cortes de 1518: "22. Otro si que porque la provision del arzobispado de Tolero al sobrino de Xebres se hizo fue y es tan dañosa a estos Reynosa si por aver sido y ser el dicho Xebres enemigo de la cosa pública destos rreynos como por ser el dicho su sobrino de muy poca edad no perteneciente para tan gran dinidad como por estar ausente de la dicha dinidad y se ayer de sacar la Renta della fuera del Reyno y no se mantener e sostener con ella muchos nobles cavalleros e hijos de grandes que estaban o se criavan en la casa de los arzobispos pasados que se hable e platique en la forma y manera que esto se puede Remediar e que

hecho de Mr. de Gebres y demás privados flamencos, que estos escudados con ella, lo disponían todo á su arbitrio, monopolizando todos los destinos y favores, y saqueando á España por cuan tos medios pudo discurrir su avaricia, y llegando su imprudencia hasta el estremo de hacer alarde, insultando á los españoles á quienes llamaban sus indios, porque tan impunemente les permitían enriquecerse. $\mathrm{La}$ estraccion de dinero para Flandes llegó á ser tan escandalosa, que agotó la moneda particular la de oro, tanto que á vista de alguna moneda de dicho metal, se hacian estremos de admiración cantando públicamente por las calles".

16 P. Mártir de Anglería, Epistolario III, op. cit., p. 246, carta 580 de 9 de diciembre de 1516.

17 P. Mexía, Historia del Emperador Carlos V, ed. de J. M. Carriazo y Arroquia, Espasa Calpe, Madrid, 1945, pp. 132-133 justifica esta actitud de los flamencos y la decisión de Carlos I de concederles puestos de relevancia.

18 M. Danvila y Collado, op. cit., Vol. II, p. 670. Carta del Cardenal Adriano al Emperador de 23 de diciembre de 1520: "los grandes y pequeños destos Reynos generalmente se quexan diziendo que han sydo tratados de v. al. [Vuestra Alteza] como si fuessen turcos y no subditos suyos".

19 Referencias A. Fernández Collado, http://dbe.rah.es/biografias/15162/guillermo-jacobo-de-croy (consultado el 13/05/2020). Cf. también A. Poschmann, "El cardenal Guillermo de Croy y el arzobispado de Toledo", Boletín de la Real Academia de la Historia, 75,1919 , pp. 202-282. hallandose tal forma como justicia se pueda hazer que no faltara bien pensado en ellos que se remedie e que nuestros procuradores sean en ello" 20 .

El Cardenal de Croy murió con veintitrés años de una caída de caballo el 6 de enero de 1521, nunca pisó en vida la diócesis toledana. Este nombramiento muestra la concepción de Carlos I del poder y la dignidad regia, nada, ni nadie podía oponerse a sus deseos, voluntad y autoridad. El reino constituía su patrimonio, podía disponer de él a su voluntad, porque los intereses del rey y del reino eran idénticos, inconfundible y coincidían totalmente. Carlos I consideraba a los súbditos como vasallos y en muchas ocasiones los trataba como si fueran siervos. Él era la cabeza del cuerpo. La cabeza es necesaria para la vida de un cuerpo, por tanto, su persona era desatinado para subsistencia de Castilla.

Frente a la idea absolutista ${ }^{21}$ del poder que practicaron desde el principio el príncipe Carlos y sus allegados, las Comunidades trataron de fortalecer la participación política activa a través de sus procuradores elegidos. El desengaño y la desilusión de los estamentos sociales se transformó en hostilidad y rechazo hacia la persona y la política del monarca y se llegó a cuestionar su derecho a ser rey estando viva su madre, la reina propietaria de Castilla.

Cuando un grupo social cuestiona la legitimidad y la capacidad de alguien para desempeñar un puesto de responsabilidad pública, tiene la necesidad ineludible de oponer otra legitimidad y a otra persona. Esta sólo podría ser la que representaba Juana I de Castilla, que estaba apartada de toda actividad política y carecía de cualquier responsabilidad de gobierno, porque se la consideraba incapacitada y enferma. No en vano ha pasado a la historia como Juana la Loca ${ }^{22}$.

La primera resolución de las instrucciones de Valladolid consistió en conocer la verdadera naturaleza de la enfermedad que la aquejaba, valorar si ésta se podría curar y si estado le permitiría asumir tanto el cuidado de sí misma como las obligaciones inherentes al cargo de reina, es decir, si estaba capacitada o no para gobernar ${ }^{23}$. La única esperanza de los comuneros se cifraba en lograr que la reina fuera capaz de asumir sus funciones y restituirla en todas sus obligaciones. Si lo conseguían, podrían afirmar que el príncipe Carlos no era el legítimo rey, sino que había usurpado el trono y arrebatado la corona a su madre. Por tanto, todos sus nombramientos y resoluciones carecían de validez.

Transcripción de J.J. Jerez Calderón, op. cit., p. 608.

21 Cf. S. Haliczer, Los Comuneros de Castilla: la forja de una revolución (1475-1521), Valladolid, Universidad de Valladolid, 1987; P. Sánchez León, Absolutismo y Comunidad. Los orígenes sociales de los Comuneros de Castilla, Madrid, Siglo XXI Editores, 1998; P. L. Alonso Baelo, Castrillo y el Tractado de República (o De la República en la ocasión de las Comunidades de Castilla, pp. 4-5 en https:// www.saavedrafajardo.org/Archivos/NOTAS/RES0044.pdf (consultado el 19 de mayo de 2020),

22 L. Pfandl, Juana la Loca, Madrid, Espasa Calpe, 1946; M. Fernández Álvarez, Juana la Loca. La Cautiva de Tordesillas, Madrid, Espasa, 2000, $2^{\mathrm{a}}$ ed.

23 J.J. Jerez Calderón, op. cit., p. 603: "Primeramente que se sepa e aberigue con mucha diligencia sy la enfermedad de la rreyna nuestra Señora es curable e sy lo fuere con mucha diligencia se cure porque sy nuestro Señor pluguiere darle entera salud ella por su rregiese e gobernase estos sus rreynos porque no paresce que ha avido muy gran ynigligencia o no sabemos que mas digamos en no se aver entendido en la cura de su rreal magestad y que entretanto que se cura sea guardada amparada y defendida por las comunidades destos rreynos e que ella tenga la guarde de su personal rreal". 
El objetivo principal de los comuneros en 1520 fue la rehabilitación de la reina Juana, reponerla en sus obligaciones y pedirle que asumiera un papel que le correspondía en la política de Castilla. Además, como el rey se había marchado a Alemania ${ }^{24}$ la única autoridad que quedaba era la Junta que se constituyó en el poder legítimo para mandar y gobernar en Castilla.

La Junta se trasladó a Tordesillas en septiembre de 1520 y allí tomó el nombre de Cortes y Junta General del Reino. Las primeras visitas de los comuneros a la reina generaron grandes expectativas. Parecía que Juana, si se le aplicaba el tratamiento y los cuidados adecuados, podría curarse, restablecerse y llegar a asumir las obligaciones propias de una reina ${ }^{25}$. La reina cayó en otro estado de apatía y todas las ilusiones del principio se vieron defraudadas ${ }^{26}$. Los comuneros perdieron la única legalidad que podían oponer a Carlos I. Se resignaron a aceptarlo como rey y usar su nombre precedido por el de su madre tal como había determinado el Consejo Real en 1516 a instancias del Cardenal Cisneros.

Para mantener vivo el movimiento social y político se vieron obligados a concentrar todas sus energías y sus fuerzas en conseguir una reforma de política que incrementara la participación de las comunidades en el gobierno del reino ${ }^{27}$. Esta actitud mereció una dura censura por parte de fray Antonio de Guevara que calificó las pretensiones de los comuneros como aquellos que "quitan reyes para hacerse reyes"28

Esta actitud mostró que los comuneros no eran antimonárquicos, que aceptaban la monarquía como forma de Estado y de gobierno para Castilla. No admitían el título imperial de Carlos V, rechazaban ser gobernados por un regente extranjero (el Cardenal Adriano de Utrecht) y dos virreyes castellanos (el Condestable y el Almirante de Castilla). Tampoco reconocían la autoridad del Consejo Real y el nombramiento de otros altos cargos que recayeron en extranjeros. Este repudio a todos los colaboradores nombrados por el rey y a su forma de gobernar como un monarca investido de un poder omnímodo, iba acompañado de una propuesta de reforma que se puede concretar en una especie de forma monárquica pactada entre el rey y el pueblo.

\section{Carlos V el Emperador}

Durante la estancia en España de Carlos I acontecieron dos hechos importantísimos en su vida que modificaron

24 Mercurino Arborio Gattinara, una persona clarividente y estrecho colaborador del rey Carlos I, además, fue quien diseñó la estrategia para conseguir la Corona Imperial, calificó este viaje como un gran error, porque el rey dejaba a sus espaldas un reino en una situación política inestable, con muchos problemas sociales y necesitado de una mano fuerte que empuñara el timón del gobierno.

25 M. Danvila y Collado, op. cit., Vol.I, pp. 471-472 en la que el Cardenal Adriano acusó a los comuneros de intentar aprovecharse de la debilidad de la reina Juana I e incluso de raptarla, carta fechada en 1 de noviembre de 1520 .

26 P. Mártir de Anglería, Cartas de Pedro Mártir sobre las Comunidades, edición de J. de la Canal. San Lorenzo del Escorial, Imprenta del Real Monasterio de El Escorial, 1945, carta 684, p. 44: "Ella vive siempre en su eterna melancolía, odiando los negocios”.

27 J. A. Maravall, op. cit., p. 152.

28 A. de Guevara, Epistolas familiares, vol. I, Madrid, Ediciones Atlas, 1945, p. 267. sus planes en Castilla. El 12 de enero de 1519 moría Maximiliano I, Emperador y abuelo de Carlos. Ese mismo año el 28 de junio en Frankfurt am Main fue elegido Emperador. La elección no fue fácil por la calidad y la importancia de los otros pretendientes los reyes Enrique VIII de Inglaterra y Francisco I de Francia. El coste de la operación fue elevado y los recursos para sufragar esos cuantiosos gastos solo podía conseguirlo mediante nuevos impuestos que se gravaban a los súbditos castellanos $^{29}$.

La designación como Emperador provocó la necesidad de convocar Cortes para obtener urgentemente una elevada cantidad de dinero para satisfacer las demandas económicas de los electores imperiales, pagar los préstamos que había solicitado a los banqueros Függer y Welser y hacer el viaje para recibir la dignidad imperial. Las urgencias en política no son las mejores consejeras, pero la necesidad apremiaba al recién nombrado Rey de los Romanos $^{30}$.

La polémica entre los súbditos castellanos se centró en tres aspectos. ¿Era legítimo convocar Cortes porque lo necesitaba el rey no por necesidades del Reino?; ¿Querían los castellanos que su rey también fuera emperador?; ¿Debían las ciudades de Castilla pagar un servicio para algo que era ajeno a la política del Reino?

Tres cuestiones relacionadas con tres ideas política. La primera un rey no debe ausentarse de sus reinos sin motivo justificado, su presencia en ellos es necesaria para la buena gobernación de los mismos. La segunda, es la objeción fiscal a un impuesto abusivo que no está relacionado con el interés del Reino. La tercera enlazada con la primera, los extranjeros no deben ocuparse de los asuntos de un reino del que no forman parte. En el fondo, se estaba cuestionando la legitimidad del poder de la Corona para imponer nuevos impuestos muy gravosos y para delegar el gobierno de los territorios en otra persona.

La ciudad de Toledo protestó contra la elección imperial porque consideraba que obedecía solo a los intereses del rey y no a los intereses políticos de Castilla. No deseaba que el Reino se convirtiera en un territorio más subordinado al Imperio. Toledo instigó a otras ciudades con representación en Cortes para que se opusieran al viaje del rey y al servicio extraordinario. Y, en caso de que tuviera que ausentarse, la regencia debía de recaer en alguien natural de Castilla. Toledo planteó algo novedoso y, en cierta manera revolucionario. La propuesta era la siguiente, si el monarca se ausentaba de su reino, los pueblos tenían el derecho a gobernarse a sí mismo con los órganos de regimiento que ellos crearan ${ }^{31}$. En el fondo se estaba reivindicando una autonomía política

\footnotetext{
9 J. Pérez, op. cit., p. 130.

30 El rey de romanos era el monarca que había sido elegido por el Colegio Electoral del Sacro Imperio Romano Germánico y que todavía no había sido coronado y ungido en Roma por el Papa, imitando la coronación de Carlomagno el día de Navidad del año 800. Por tanto, es un emperador elegido que le falta la coronación que es como la toma de posesión del cargo. M. Fernández Álvarez, "El proyecto europeo de Carlos V”, en F. Martínez Gil (ed.), Entorno a las Comunidades de Castilla. Actas del Congreso Internacional Poder, Conflicto y Revuelta en la España de Carlos I, Toledo, Universidad de Castilla-La Mancha, 2002, pp. 551-565.

31 J. Pérez, op. cit., 136.
} 
amplia y el reconocimiento que un pueblo solo se sometía a la voluntad de un rey legítimo que cumplía con su deber de velar por la integridad de sus territorios y el bien de los súbditos. Esta idea fue uno los motivos por los que se produjo la rebelión de los comuneros.

El malestar y el descontento de las ciudades se plasmó en lo que se conoce como el Programa o Manifiesto de Salamanca. Un punto esencial en la discusión de las ideas políticas fue fijar el poder de representación de los diputados. Éste era muy impreciso y se planteó otorgar al representante de la ciudad un poder limitado por un mandato imperativo, esto es, los diputados expondrían las reivindicaciones, que el rey estaba obligado a conceder como una condición previa y necesaria para votar el servicio ${ }^{32}$. Si el monarca no aceptaba la exigencia, el diputado debía votar negativamente la petición del rey. La cuestión de quién es el depositario legítimo del poder, era evidente para los comuneros, el reino y no el rey. Aquél mandaba sobre éste ${ }^{33}$.

Desde este punto de vista, el rey queda obligado a atender las peticiones del pueblo y éste, en consecuencia, le presta su auxilio y le otorga los medios para realizar los proyectos políticos que propone. El orden se ha invertido y la lógica es condicional, si aceptas la propuesta, entonces el pueblo te ayudará, en caso contrario no recibirás la ayuda. El reino estaba por encima del rey y los representantes en Cortes eran los portavoces del reino. Las Cortes no dependían del rey ni del Consejo Real para ser convocadas ${ }^{34}$.

En las reivindicaciones se presentaron se planteó una cuestión esencial, las ciudades castellanas, o al menos un buen número de ellas, deseaban tener un rey que residiera en Castilla y gobernara el reino, para olvidar los quince años de calamidades e inestabilidad política que se habían vivido desde la muerte de la reina Isabel la Católica en 1504. Un rey que se ocupara de sus asuntos y que construyera un proyecto político para Castilla y de este reino proyectarlo a todos los territorios patrimoniales de Carlos I. Dicho de otra manera, los comuneros proponían que Castilla fuera el centro de la política del monarca Carlos I. Por esta razón se rechazaba el título imperial, porque se oponía a un posible/futuro imperio castellano.

En este tiempo se inició un profundo cambio en la idea de representación política de los procuradores en Cortes. ¿Qué era el reino y quién pertenecía a él? El orgullo de pertenencia al Reino de Castilla condujo a los castellanos a pensar que se había constituido un reino con una gran proyección en la Historia. Castilla después de siglos había conseguido tener una presencia destacada en la política europea. Se habían superado las épocas turbulentas de guerras intestinas y se habían realizado grandes gestas que acrecentaban el poder y el dominio de Castilla sobre diversos y dispersos territorios. La estructura social constituía una entidad política unitaria y territorial compuesta por el rey en la cúspide y tres

\footnotetext{
J. Pérez, op. cit., pp. 142-148.

J. A. Maravall, op. cit., pp. 161-162.

34 J. Pérez, op. cit., pp. 249-250; J. M. Carretero Zamora, "Las Cortes en el programa comunero. ¿Reforma institucional o propuesta revolucionaria?", en F. Gil Martínez (ed.), op. cit., pp. 233-278.
}

estamentos sociales, la nobleza, el clero y el pueblo. El oficio del rey era gobernar rectamente para buscar el equilibrio entre los estamentos sociales y la armonía de éstos con él mismo. Las dos partes formaban una unidad comprometida en un mismo proyecto. El pacto tácito era que cada una de ellas debía cumplir con sus funciones, obligaciones y respetar los derechos de la otra. Si se traspasaba estos límites, se rompía el pacto, se quebraba la unidad y se disolvía el compromiso. El bien del monarca y el bien común el reino se diferenciaban y se convertían en dos fines independientes y cada parte lucha por verlo hecho realidad e imponerlo a la otra.

Carlos I escuchó todas las propuestas, pero no cumplió ninguna de las promesas. Las peticiones eran muy concretas y con ellas se pretendía garantizar la independencia de Castilla del Imperio, es decir, Castilla no tenía que estar sometida a la política imperial. En caso de nombrar un regente o gobernador del reino que este fuera castellano y no extranjero.

Esta actitud tiene su justificación en la propuesta del insigne jurista Juan López de Palacios Rubios. En su opúsculo De beneficiis in curia vacantibus, escrito en Roma mientras era embajador y en defensa del patrimonio real, afirmó que los reyes de España, en virtud de que son los legítimos herederos de los reyes godos, poseen un derecho pleno de patronato en las iglesias de sus reinos, concesión fue realizada por el papa Honorio I. Este hecho le llevó a afirmar que los reyes de España no reconocen superior alguno, ni emperador ni otro rey, en el ámbito temporal. Todos tienen una plenitudo potestatis exenta de dominio de otro ${ }^{35}$. Esta cuestión subyace en las críticas a la elección imperial y a la legitimidad para aceptarla e imponer un servicio especial a los castellanos para sufragar los gastos de una dignidad que podía convertir al Reino de Castilla en un apéndice de la política imperial ${ }^{36}$.

Uno de los puntos fundamentales que justificaron el movimiento de las Comunidades fue el rechazo a la idea de convertir el reino de Castilla en una monarquía universal que obligara al rey a viajar y a estar ausente largas temporadas. Esta concepción de la monarquía se podría calificar como patrimonialista. Su característica fundamental es que concebía la función de reinar como hemos dicho antes, sobre un territorio concreto, sobre los súbditos que viven en él, con unas leyes pactadas

J. López de Palacios Rubios, Libellus de Beneficiis in Curia vacantibus, Salmantice, Ioannes de Porras, 1517.

36 Cf. la transcripción del documento en M. Dánvila, op. cit., vol. I, 272-274, es significativo la parte del texto donde se dice, p. 273: "Sy esto no oviere lugar, le hagan un requerimiento con tres o quatro escrívanos que si algo se hiziere conplidero al bien destos reynos de que su alteza, a parecer de los que le aconsejan la partida, no se tenga por servido, que las Comunidades destos reynos no caigan por ello en mal caso, que más obligadas son al bien destos reynos en que biben que no a lo que pareciere a los que le aconsejan la partida y más es su servicio estar en ellos a governarlos por su presencia que absentarse y en caso que no aproveche nada este requerimiento, pedir al rey nuestro señor tenga por bien se hagan arcas de thesoro en las Comunidades en que se guarden las rentas destos reynos para defendellos e acrescentarlos e desenpeñarlos, que no es razón Su Cesárea Magestad gaste las rentas destos reynos en las de los otros señoríos que tiene, pues cada qual dellos es bastante para si, y este no es obligado a ninguno de los otros ni subjeto ni conquistado ni defendido de gentes estrañas". 
entre el rey y los gobernados y con unas instituciones que ordenan y controlan el ejercicio del poder por parte del rey. Es la forma de entender el gobierno en el territorio y para los súbditos ${ }^{37}$. El modelo para los comuneros fueron los Reyes Católicos que se ocuparon de organizar jurídica, social y políticamente sus reinos patrimoniales, completaron la reconquista de los territorios ocupados por los musulmanes y gobernaron otras tierras que fueron incorporando a la Corona desde Castilla.

Carlos I aceptó todas esas peticiones, pero no cumplió ninguna. Reinó sin sentirse comprometido por sus promesas o sus buenas palabras. Esta actitud del rey provocó un rechazo tanto a la persona como a las exigencias del monarca y de sus colaboradores, que se dedicaban a ejercer presión sobre los procuradores con amenazas para conseguir su voto afirmativo al servicio que se solicitaba. No querían acabar con la monarquía como forma de Estado y de gobierno y sustituirla por otro régimen político, sino que rechazaban la manera gobernar y las decisiones de Carlos I. Rechazaban y se rebelaban contra la imposición por la fuerza del poder, la exigencia de una sumisión absoluta a los proyectos de la Corona, el sueño de una política imperial centrada en Europa y el dominio que los extranjeros ejercía en todas las instituciones del reino.

El viaje de Carlos I a Alemania, unida a su falta de atención a los problemas planteados y la forma de gobernar de su regente y de los virreyes, llevaron a los comuneros buscar una alternativa política para gobernar Castilla. En el verano de 1520 se reunieron en Ávila y establecerán un órgano que se llamó Santa Junta, que se atribuyó la representación de todo el cuerpo político ${ }^{38}$. Desde el principio se atribuyó la capacidad y, también, la necesidad de gobernar Castilla en nombre de la reina Juana I, porque su hijo había abandonado su reino. En esta situación su poder y la legitimidad de sus decisiones contaron con el respaldo de los municipios y ciudades representadas en ella ${ }^{39}$.

Pedro Mártir de Anglería informó por carta al Canciller Gattinara ${ }^{40}$ el 23 de octubre de 1520, relataba las discrepancias y las objeciones que Burgos ponía a las resoluciones y política seguida por la Junta. "Burgos ciudad principal a acusado por sus procuradores a los junteros de que se hayan atrevido a insultar a los Consejeros, y haber admitido la proposición de quitar al Rei el nombre tal, que se le dio ya. Le dicen que ellos los auxiliarían si se tratase de los gravámenes del reino solamente y de la observación de las leyes patrias: Pero

$37 \quad$ La revuelta de los comuneros fue calificada como un movimiento de marcado carácter nacionalista por J. H. Elliot, La España Imperial, Vicens Vives, Barcelona, 1963, p. 152 y M. Fernández Álvarez, "Derrota y triunfo de las Comunidades", Revista de Occidente, 149-150, 1975 , p. 243

38 M. Diago Hernando, "La representación ciudadana en las asambleas estamentales castellanas: Cortes y Santa Junta Comunera. Análisis comparativo del perfil sociopolítico de los procuradores", Anuario de Estudios Medievales, 34/2, 2004, pp. 599-665, es quizás el estudio más completo y documentado sobre esta institución política.

39 M. Danvila y Collado, op. cit., Vol. II, pp. 76-81, donde se recoge el texto que la Alianza y hermandad jurada que las ciudades y villas del Reino realizaron en Tordesillas el 25 de septiembre de 1520; P. Mexía, op. cit., p. 170.

40 M. Rivero Rodríguez http://dbe.rah.es/biografias/10612/mercurinoarborio-gattinara (consultado el 14 de mayo de 2020). protestan que no tomarán parte en sus necesidades, si piensan en usurparse la autoridad de gobernar", y más abajo sentenció "los Junteros hechos Reyes con pretesto de libertad" 41 . El resumen que hace este humanista es muy ajustado. Burgos está dispuesta a forma parte del movimiento siempre que no se traspasen los límites impuesto por el orden jurídico vigente. La apreciación de que han usurpado el título de rey cuando ya había sido reconocido, proclamado y jurado significa que los comuneros se consideran por encima de la autoridad real y ellos mismos actúan como el único poder legítimo en el reino. La última frase es una apreciación personal del autor, pero revela que el proceso estaba muy avanzado y que los comuneros, en nombre de la libertad del pueblo y del reino, actuaban como si fueran reyes. Era evidente que para este autor las Comunidades pretendían un cambio constitucional.

\section{El rechazo al Imperio}

Las Cortes de Santiago de 1520 se reunieron en el convento de San Francisco presididas por el Gran Canciller, Mercurino Gattinara y el obispo de Badajoz, Pedro Ruiz de la Mota. Fue el obispo el encargado de abrir las sesiones con un discurso en el que trató de atraer a los procuradores reticentes a votar el servicio y a los que se oponían a aceptar la designación de Carlos I como emperador. Toda la argumentación giraba en torno a cinco ideas fundamentales:

1. El Obispo Ruiz de la Mota comenzó enalteciendo a la persona, la figura histórica y política y la dignidad de Carlos V. Afirmó que no fue un Rey como todos los demás, porque tiene más reinos que cualquier otro ${ }^{42}$.

2. La segunda idea destacable de su discurso es la explícita y clara declaración de amor del rey por Castilla. La consideró como el núcleo fundamental de su poder afirmando que estaba dispuesto a aprender la lengua y apreciaba las costumbres, los usos y los modos de Castilla. El rey estaba haciendo desde su llegada a España un gran esfuerzo por hispanizarse, y como prueba de este afecto por lo español y su admiración hacia Castilla prometió regresar a no más tardar tres años desde su partida. Su voluntad y su deseo vehemente era vivir y morir en España. Con esta manifestación pretendía acallar los rumores sobre que iba a ser un rey ausente y que su viaje a Alemania no tendría fecha de retorno, su ausencia no iba a ser indefinida ${ }^{43}$.

3. Explicó el significado de la dignidad imperial y el deber que supone asumirla para el rey. Ser emperador significa afrontar un liderazgo universal que implica también deberes universales.

\footnotetext{
P. Mártir de Anglería, Cartas de Pedro Mártir sobre las Comunidades, op. cit., carta 693, p. 56.

42 J. A. Muñoz Gallardo, "Carlos V y el obispo de Badajoz", Revista de Estudios Extremeños, 27/1, 1971, pp. 14-15.

43 M. Fernández Álvarez, Carlos V, el César y El hombre, Madrid, Espasa, 1999, p. 122.
} 
La elección como Emperador tiene un origen divino que le convierte en el defensor del imperio cristiano. Su misión es combatir a cualquier enemigo de la fe cristiana, tanto en los territorios de la Cristiandad, como a los infieles. En esto fueron modelo sus abuelos, los Reyes Católicos ${ }^{44}$.

4. La cuarta idea trata de mostrar que la dignidad imperial no restará protagonismo a Castilla. El Reino del que es titular Carlos será el centro y el núcleo de la nueva monarquía que construirá un imperio universal, digna heredera de los grandes emperadores que dio Hispania a Roma. Trajano, Adriano y Teodosio. En esta misma línea justificó el viaje que tenía que realizar el rey, cuya duración debe ser limitada. Tras ese viaje España se convertirá en el centro desde donde realizará su proyecto político universal.

5. En el quinto y último punto, muestra cómo el elegido emperador Carlos V, tiene tantos reinos, señoríos, dominios por la herencia recibida de sus dos ramas familiares, que no pide ni necesita nada más. Su humildad le lleva a aceptar el título imperial para restaurar, como su abuelo Fernando el Católico, el imperio cristiano que le otorgará más gloria a España por ser el centro desde el que se realizará ese proyecto político universal ${ }^{45}$.

Parecía que con la intervención del obispo de Badajoz de cerraba la sesión inaugural de las Cortes. Pero contra todo pronóstico y no estando previsto el emperador Carlos V tomó la palabra y en un fluido y correcto castellano, mostrando que era capaz de comunicarse en la lengua de sus súbditos. Ratificó que todo lo que había dicho el obispo y consejero era en su nombre. En su intervención destacó tres puntos. Primero, confesó que le resultaba molesto y mostraba su contrariedad por tener que emprender un largo viaje fuera de España. No se alegraba por partir, pero tenía que hacerlo para ser emperador y con esto beneficiar a sus reinos por encima de sus preferencias. Segundo, el viaje y su ausencia no durarían más de tres años contados desde el día de su partida. Tercero, prometió no conceder beneficios, oficios, cargos y sinecuras a extranjeros.

Tanto el discurso del obispo de Badajoz, como la posterior intervención del monarca, eran muestra de la tensión que se vivía en la Cortes y el rechazo que provocaba la actitud de Carlos I en los súbditos del Reino de Castilla. Toda la argumentación está orientada a disipar los miedos de los asistentes a que Castilla se convirtiera en una pieza más sin importancia en el proyecto político

44 Ibidem. En la sala conocida como el Incendio del Borgo en el Vaticano, en 1515 se representó a la Fernando el Católico en vida. La escena tiene esta composición. A sus lados, protegiendo al monarca español, están dos grandes reyes de la Cristiandad, el emperador Carlomagno, restaurador del Imperio de Occidente, y Godofredo de Bouillon, el conquistador de Jerusalén en el año 1099. En el lugar se puede leer la leyenda Ferdinandus Rex Catholicus, Christiani Imperii Propagator (Fernando, Rey Católico, Conquistador del Imperio Cristiano).

45 J. A. Muñoz Gallardo, op. cit., pp. 15-16. imperial de Carlos V. Los castellanos no querían tener ni más ni menos protagonismo en el proyecto político de monarquía universal carolina, sino tener un rey que se ocupara de su reino y del bienestar de sus súbditos. No pedían nada más que el rey cumpliera con los deberes que le impone su cargo y posición. En el discurso no se ofrece una solución a este problema y a esta preocupación, por eso no convenció a los asistentes. La narración de los hechos muestra que se vivían unos momentos de crisis. Es decir, todos eran conscientes de que en las Cortes se estaba produciendo una mutación y que el curso de la vida política no podría ser igual después de los hechos que se estaban viviendo. El rey, su corte y los procuradores son testigos, protagonistas e impulsores de un cambio irreversible que era consecuencia del largo período de inestabilidad que se había vivido desde la muerte del príncipe Juan de Trastámara, que enterró tantos proyectos e ilusiones, hasta la llegada de Carlos I en 1517. Para Castilla y los castellanos se abrían varios caminos y posibilidades. Tenían que elegir una y olvidar los demás. Esta situación marcó el inicio de la revuelta de las Comunidades.

En Castilla existía una fuerte corriente de oposición a la elección imperial, porque como se ha dicho no deseaban ver reducido el protagonismo del reino de Castilla en la política europea, o que sus proyectos dependieran de una entidad supranacional. Durante el reinado de los Reyes Católicos se incorporaron a la Corona diversos territorios que se fueron conquistando y descubriendo. Se formó una auténtica monarquía universal que tenía posesiones en Europa, África y América. La inmensa herencia de Carlos I se vio acrecentada con la elección como Emperador. Un título que le convertía en un monarca superior a todos los demás. Para Carlos I Castilla constituía un reino en el que podía conseguir los recursos necesarios para realizar su política imperial. Para los castellanos las pretensiones de su rey y Emperador las valoraba de otra manera. Castilla en el conjunto de los reinos de Carlos I sería un apéndice o, mejor dicho, una prótesis extraña que no formaría, o en el mejor de casos, no se identificaría totalmente con el proyecto político que el monarca planeaba.

En este caso se produjo no sólo un choque de mentalidades, sino también una diferente apreciación del significado del Imperio. Para Carlos V era la culminación de un ambición familiar y personal. Para los castellanos una amenaza a la independencia del Reino y a la libertad de los súbditos del rey ${ }^{46}$. Veían que el rey de Castilla ganaba en dignidad, pero ellos perdían a la persona que tenía que gobernarles y regir toda la extensión territorial que correspondía al heredero de los Reyes Católi$\cos$. La colisión se produce entre una idea de imperio europeo-cristiano en el que su centro de gravedad estaba en Alemania, a Castilla no le quedaba más remedio que convertirse en una pieza más de todo el puzle; y otra idea de imperio que tuviera su centro en Castilla en la que el monarca gobierna el reino y desde él todos los territorios que lo componen. Esta última idea se basaba en una idea de monarquía patrimonial en la que el rey es

${ }^{46}$ Cf. la obra clásica de J. Ma . Jover Zamora, Carlos Vy los españoles, Madrid, Rialp, 1963. 
rey de Castilla y desde su propiedad gobierna. Ser Emperador de Alemania, como se conocía en esa época, no era más que un título honorífico ${ }^{47}$, que no aportaba nada a Castilla y sí le iba a suponer soportar grandes gastos y disponer de personas para nutrir las filas de los ejércitos. No estaban equivocados los castellanos y el tiempo les dio la razón.

\section{Conclusiones}

El debate sobre la preminencia del reino sobre el rey se zanjó con la victoria de las tropas del Carlos I el 23 de abril de 1521 en Villalar. La cuestión quedó solventada con una frase: el rey era el reino y el reino era del rey. La situación está resumida en el principio recogido en las Instituciones de Justiniano: "Sed et quod principi placuit, legis habet vigorem" 48 , lo que el príncipe desea o le parece bien, tiene fuerza de ley. Es decir, primero hay que aceptar lo que quiere el rey y, después, éste concederá su gracia si le parece oportuno, conveniente y necesario para bien del reino y el bienestar de los súbditos. Dos formas antagónicas de entender la función de las Cortes y del poder de los representantes y del rey.

Se ha escrito y publicado que los comuneros de Castilla fue un movimiento social que trató de instaurar una nueva constitución en Castilla, "merced al suceso de Villalar, el devenir constitucional español tomó tal rumbo que, mirando al fondo de las cosas, no se ha rectificado todavía"49. Para otros fue una revolución, o dicho con más precisión, fue la primera revolución moderna, en palabras de J.A. Maravall ${ }^{50}$. Dentro de esta revolución se ha considerado un movimiento antiseñorial, contra la nobleza que trató de monopolizar los cargos políticos y el gobierno de Castilla ${ }^{51}$. En la revisión sobre el carácter y el sentido del movimiento comunero, sobre si se puede o no calificarlo de revolución, han participado varios historiadores, entre ellos Julio Valdeón insistió en la idea

47 H. Kamen, Imperio. La forja de España como potencia mundial, Madrid, Aguilar, 2003, p. 26; J. J. Jerez Calderón, op. cit., pp. 133135; E. Berzal de la Rosa, Los Comuneros. De la realidad al mito. Madrid, Silex Ediciones, 2008, pp. 41-70.

48 Justiniano, Institutiones, I, 1,2,6: "Sed et quod principi placuit, legis habet vigorem, cum lege regia, quae de imperio eius lata est, populus ei et in eum omne suum imperium et potestatem concessit. Quodcumque igitur imperator per epistulam constituit vel cognoscens decrevit vel edicto praecepit, legem esse constat: hae sunt, quae constitutiones appellantur".

49 M. Azaña, Plumas y palabras, Barcelona, Crítica, $19903^{\text {a }}$ ed., p. 54. En este sentido también se pronunció el historiador inglés H. L. Seaver, The Great Revolt in Castile. A Study of the Comunero Movement of 1520-1521, London, Constable \& Company Limited, 1930; E. Tierno Galván, “¿Es el Lazarillo un libro comunero?”, en Boletín Informativo del Seminario de Derecho Político, Universidad de Salamanca, Salamanca, noviembre-diciembre, 1957, "De las Comunidades o la historia como proceso", en Boletín Informativo del Seminario de Derecho Politico, Universidad de Salamanca, Salamanca, mayo-octubre, 1957, textos publicados en Escritos (1950-1960), Tecnos, Madrid, 1971.

50 J. A. Maravall, op. cit., es una obra de referencia para los historiadores; J. Pérez, op. cit., corrobora esta idea y la utiliza como guía para su trabajo.

51 J. I. Gutiérrez Nieto, Las comunidades como movimiento antiseñorial, Barcelona, Planeta, 1973. de las Comunidades como última revuelta medieval ${ }^{52}$, tradicional, pero no retrógrada. Pablo Sánchez León, que afirmó que fue una revuelta urbana y no una revolución porque unos nobles o caballeros de las ciudades de Castilla no podían tener la idea de llevar a cabo una revolución ${ }^{53}$. En el mismo sentido se pronunció el historiador Máximo Diago Hernando ${ }^{54}$. Más desarrollada está la tesis de Pablo Fernández Albadalejo, al matizar el mismo objeto de debate sobre el carácter feudal o revolucionario de las Comunidades, subrayando más la restauración del orden jurídico que la nota revolucionaria ${ }^{55}$.

Podríamos preguntarnos si los comuneros estaban proponiendo una constitución nueva o una reforma profunda de las leyes y las normas que ordenaban el gobierno de la monarquía. Si se acepta que las Comunidades en sus sucesivas instrucciones pretendieron imponer una nueva constitución política, entonces, los comuneros provocaron una revolución porque exigían un cambio de régimen político. Si no admitimos el cambio constitucional, habrá que convenir que las Comunidades fueron una rebelión que pretendió realizar reformas políticas y, también, sociales de profundo calado.

Los comuneros lo que buscaron fue una reforma profunda de la monarquía como forma de Estado y de gobierno, que incluía conseguir un régimen representativo de todos los estamentos sociales. Para lograr sus objetivos tenían que potenciar las Cortes como institución política que representaba a todo el cuerpo político y al reino. La propuesta exigía fundamentar teóricamente esta reforma.

Las Comunidades trataron instaurar una monarquía en la que se incrementara la participación del tercer estamento social, el pueblo (comunidad), en el gobierno del reino y en el control del ejercicio de las responsabilidades políticas. Para eso propusieron limitar el poder real, darle más importancia y fuerza a la representación de los municipios en las Cortes y disminuir todo lo posible la presencia de la oligarquía nobiliaria en el gobierno ${ }^{56}$. Esta reforma política que planteaban los comuneros tendría que establecer una nueva monarquía que se podría denominar como una monarquía democrática o bien una democracia coronada. En este contexto los comuneros se comprometieron a apoyar al rey en sus proyectos de reforma que veían necesarias.

Por otro lado, la fundamentación teórica estaba en una reformulación del pacto que no era una costumbre extraña en Castilla ${ }^{57}$ aunque se había desarrollado

J. Valdeón Baruque, “¿La última revuelta medieval?”, Cuadernos Historia 16, 24, 1985, pp. 4-12.

53 P. Sánchez León, Absolutismo y Comunidad. Los orígenes sociales de la guerra de los comuneros de Castilla, Madrid, Siglo XXI Editores, 1998, "La Constitución histórica del sujeto comunero: orden absolutista y lucha por la incorporación estamental en las ciudades de Castilla, 1350-1520”, en F. Martínez Gil (ed.), op. cit., pp. 159-208.

54 M. Diago Hernando, Le Comunidades di Castiglia (1520-1521). Una rivolta urbana contro la monarchia degli Asburgo, Milano, Edizioni Unicopli, 2001.

55 P. Fernández Albadalejo, Fragmentos de Monarquía, Madrid, Alianza, 1992, p. 54.

56 J. J. Jerez Calderón, op. cit., pp. 221-232.

57 A. García Gallo, "El pactismo en el Reino de Castilla y su proyección en América", en El pactismo en la historia de España, Madrid, Instituto de España, 1980, pp. 143-168; A. I. Carrasco Manchado, 
más en Aragón ${ }^{58}$. El pacto impone límites al ejercicio del poder político. Estos límites vienen determinados por las siguientes ideas que defendieron los comuneros. El origen del poder está y procede en el pueblo como cuerpo político y antecede al rey ${ }^{59}$. Cuando el rey es coronado goza de un amplio poder, que está limitado en virtud del pacto entre él y el pueblo. El poder del rey le impone la obligación de proteger a sus súbditos, conservar su heredad y gobernar la comunidad con justicia y de acuerdo con las leyes. A cambio, los súbditos se comprometen a servir al rey en todas sus necesidades y secundarlos en sus proyectos con lealtad y devoción a su persona. Los súbditos son libres y autónomos en todo lo que no está prohibido y regulado por el derecho. Las reglas que rigen la relación entre los súbditos y el rey no pueden ser alteradas unilateralmente, se necesita el consentimiento del cada una de las partes, de ahí la apelación a las leyes tradicionales de Castilla ${ }^{60}$.

La teoría más adecuada es el pactismo. En este sentido el pacto tiene dos caras como la cabeza de Jano. Una cara es el pacto que se realiza para construir la comunidad política. La otra faz es el pacto para nominar un gobernante. Este último es fundamental en las Comunidades porque de él se derivan deberes que legitiman al monarca y le permiten mantenerse en el trono con el apoyo y la fidelidad de los súbditos. Esta forma monárquica limita el poder del rey, lo acota y fija el modo de ejercerlo sobre la comunidad y los súbditos, que no son vasallos sino seres humanos libres.

Esta fue la justificación teórica que esgrimieron los comuneros para provocar un cambio político en la monarquía. Un régimen en el que poder del rey estaba limitado y sometido a las leyes vigentes y al acuerdo con la comunidad. El derecho ordenaba el presente y el pacto el desarrollo y el futuro del reino. Carlos I no percibió la coyuntura de la misma manera y se produjo la ruptura entre las dos partes. Políticamente se truncó la posibilidad de establecer una monarquía constitucional basada en la participación activa de los súbditos en el gobierno y el control del ejercicio del poder por parte del rey. Pero este levantamiento popular, como otros que se produjeron después, afectó a la monarquía y a la misma idea de Estado y sociedad ${ }^{61}$. Carlos I se vio obligado a introducir cambios, pero la consecuencia final fue que en la Monarquía Hispánica el rey mandó sobre el reino.

\section{Bibiografía}

Alonso Baelo, P. L., Castrillo y el Tractado de República (o De la República en la ocasión de las Comunidades de Castilla, pp. 4-5 en https://www.saavedrafajardo.org/Archivos/NOTAS/RES0044.pdf

Alvar Ezquerra, A., en http://dbe.rah.es/biografias/10081/fernando-i-de-austria

Azaña, M., Plumas y palabras, Barcelona, Crítica, $19903^{\mathrm{a}}$ ed.

Bayona Aznar, B., Pactismo y Teocracia. Las dos caras del pensamiento político de Francesc Eximenis, Madrid, Tecnos, 2019.

Berzal de la Rosa, E., Los Comuneros. De la realidad al mito, Madrid, Silex Ediciones, 2008.

Carrasco Manchado, A. I., "Entre el rey y el reino calladamente está fecho un contrato Fundamentos contractuales de la monarquía Trastámara en Castilla en el siglo XV", en F. Foronda (dir.), Avant le contrat social. Le contrat politique dans l'Occident médiéval, XIIIe-XVe siècle, Paris, Éditions de la Sobronne, 2011, pp. 613-652.

Carretero Zamora, J. M., “Las Cortes en el programa comunero. ¿Reforma institucional o propuesta revolucionaria?”, en F. Gil Martínez (ed.), Entorno a las Comunidades de Castilla. Actas del Congreso Internacional Poder, Conflicto y Revuelta en la España de Carlos I, Toledo, Universidad de Castilla-La Mancha, 2002, pp. 233-278.

Danvila y Collado, A., Historia crítica y documentada de las Comunidades de Castilla, Volumen II, Madrid, Establecimiento Tipográfico de la viuda e hijos de M. Tello, 1898.

Diago Hernando, M., "La representación ciudadana en las asambleas estamentales castellanas: Cortes y Santa Junta Comunera. Análisis comparativo del perfil sociopolítico de los procuradores", Anuario de Estudios Medievales, 34/2, 2004, pp. $599-665$.

-, Le Comunidades di Castiglia (1520-1521). Una rivolta urbana contro la monarchia degli Asburgo, Milano, Edizioni Unicopli, 2001.

Elliot, J. H., La España Imperial, Barcelona, Vicens Vives, 1963.

Fernández Albadalejo, P., Fragmentos de Monarquía, Madrid, Alianza, 1992.

Fernández Álvarez, M., "Derrota y triunfo de las Comunidades", Revista de Occidente, 149-150, 1975, pp. 234-249,

-, Juana la Loca. La Cautiva de Tordesillas, 2aed., Madrid, Espasa, 2000.

-, "El proyecto europeo de Carlos V", en F. Martínez Gil (ed.), Entorno a las Comunidades de Castilla. Actas del Congreso Internacional Poder, Conflicto y Revuelta en la España de Carlos I, Toledo, Universidad de Castilla-La Mancha, 2002, pp. 551-565.

-, Carlos V, el César y El hombre, Madrid, Espasa, 1999.

Fernández Collado, A., http://dbe.rah.es/biografias/15162/guillermo-jacobo-de-croy

"Entre el rey y el reino calladamente está fecho un contrato Fundamentos contractuales de la monarquía Trastámara en Castilla en el siglo XV", en F. Foronda (dir.), Avant le contrat social. Le contrat politique dans l'Occident médiéval, XIIIe-XVe siècle, Paris, Éditions de la Sobronne, 2011, pp. 613-652.

58 B. Bayona Aznar, Pactismo y Teocracia. Las dos caras del pensamiento politico de Francesc Exiximenis, Madrid, Tecnos, 2019.

59 J. A. Maravall, op. cit., pp. 161-162.

60 P. Sandoval, op. cit., Primera parte, 7, 2, p. 295: "las leyes de vuestros reinos que por razón natural fueron hechas y ordenadas ... así obligan a los príncipes como a los súbditos". 
García Gallo, A., "El pactismo en el Reino de Castilla y su proyección en América", en El pactismo en la historia de España, Madrid, Instituto de España, 1980, pp. 143-168.

de Guevara, A., Epistolas familiares, vol. I, Madrid, Ediciones Atlas, 1945.

Gutiérrez Nieto, J. I., Las comunidades como movimiento antiseñorial, Barcelona, Planeta, 1973.

Haliczer, S., Los Comuneros de Castilla: la forja de una revolución (1475-1521), Valladolid, Universidad de Valladolid, 1987.

Jerez Calderón, J. J., Pensamiento politico y reforma institucional durante la guerra de las Comunidades de Castilla (15201521), Madrid, Marcial Pons, 2007.

Jover Zamora, J. Mª, Carlos Vy los españoles, Madrid, Rialp, 1963.

Kamen, H., Imperio. La forja de España como potencia mundial, Madrid, Aguilar, 2003.

López de Palacios Rubios, J., Libellus de Beneficiis in Curia vacantibus, Salmantice, Ioannes de Porras, 1517.

Maldonado, J., Historia de la revolución conocida con el nombre de las Comunidades de Castilla, trad. De J. Quevedo, Madrid, Imprenta de D. E. Aguado, 1840.

Maravall, J. M., Las Comunidades de Castilla. La primera revolución moderna, $4^{\mathrm{a}}$ ed., Madrid, Alianza Editorial, 1984.

Mártir de Anglería, P., Epistolario, volumen III, editado por J. López de Toro, Madrid, Imprenta de Góngora, 1956.

-, Cartas de Pedro Mártir sobre las Comunidades, edición de J. de la Canal. San Lorenzo del Escorial, Imprenta del Real Monasterio de El Escorial, 1945.

Mexía, P., Historia del Emperador Carlos V, ed. de J. M. Carriazo y Arroquia, Madrid, Espasa Calpe, 1945.

Muñoz Gallardo, J. A., "Carlos V y el obispo de Badajoz”, Revista de Estudios Extremeños, 27/1, 1971, pp. 11-20.

Pfandl, L., Juana la Loca, Madrid, Espasa Calpe, 1946.

Poschmann, A., "El cardenal Guillermo de Croy y el arzobispado de Toledo", Boletín de la Real Academia de la Historia, 75, 1919, pp. 202-282.

Rivero Rodríguez, M., http://dbe.rah.es/biografias/10612/mercurino-arborio-gattinara

Rivero Rodríguez, A., "El mito comunero y la construcción de la identidad nacional en el liberalismo español”, en F. Colom González, Relatos de la nación: la construcción de las identidades nacionales en el mundo hispánico, Vol. 1, Madrid, Iberoamericana Vervuert, 2005, pp. 147-158.

Sáenz de Santa María Vierna, A., "El testamento del Rey Católico y la legítima aragonesa", Revista de Derecho Civil Aragonés, 21-22, 2015-2016, pp. 155-172.

Sánchez León, P., Absolutismo y Comunidad. Los orígenes sociales de los Comuneros de Castilla, Madrid, Siglo XXI Editores, 1998.

-, "La Constitución histórica del sujeto comunero: orden absolutista y lucha por la incorporación estamental en las ciudades de Castilla, 1350-1520", en F. Martínez Gil (ed.), Entorno a las Comunidades de Castilla. Actas del Congreso Internacional Poder, Conflicto y Revuelta en la España de Carlos I, Toledo, Universidad de Castilla-La Mancha, 2002, pp. 159-208.

Sandoval, P., Historia de la vida y hechos del Emperador Carlos V, Primera parte, Barcelona, Sebastián Cormellas, 1625.

de Santa Cruz, A., Crónica del Emperador Carlos V, cinco volúmenes, editado por R. Beltrán y Rózpide, A. Blázquez y Delgado Aguilera, y F. Laiglesia y Auser, Madrid, Imprenta del Patronato de Huérfanos de Intendencia e Intervención Militares, 19201925.

Seaver, H. L., The Great Revolt in Castile. A Study of the Comunero Movement of 1520-1521, London, Constable \& Company Limited, 1930.

Tierno Galván, E., “Es el Lazarillo un libro comunero?”, en Boletín Informativo del Seminario de Derecho Politico, Universidad de Salamanca, Salamanca, noviembre-diciembre, 1957, "De las Comunidades o la historia como proceso", en Boletín Informativo del Seminario de Derecho Politico, Universidad de Salamanca, Salamanca, mayo-octubre, 1957, textos publicados en Escritos (1950-1960), Madrid, Tecnos, 1971.

Valdeón Baruque, J., ¿¿La última revuelta medieval?”, Cuadernos Historia 16, 24, 1985, pp. 4-12. 